\title{
Early Development of Hearing in Zebrafish
}

\author{
Zhongmin Lu ${ }^{1,2,3}$ and Alexandra A. DeSmidt ${ }^{1}$ \\ ${ }^{1}$ Department of Biology, University of Miami, 1301 Memorial Drive, Room 4, Coral Gables, FL 33146, USA \\ ${ }^{2}$ Neuroscience Program, University of Miami, Miami, FL 33101, USA \\ ${ }^{3}$ International Center for Marine Studies, Shanghai Ocean University, Shanghai, 201306, People's Republic of China
}

Received: 21 September 2012; Accepted: 17 March 2013; Online publication: 11 April 2013

\begin{abstract}
The zebrafish (Danio rerio) has become a valuable vertebrate model for human hearing and balance disorders because it combines powerful genetics, excellent embryology, and exceptional in vivo visualization in one organism. In this study, we investigated auditory function of zebrafish at early developmental stages using the microphonic potential method. This is the first study to report ontogeny of response of hair cells in any fish during the first week post fertilization. The right ear of each zebrafish embedded in agarose was linearly stimulated with a glass probe that was driven by a calibrated piezoelectric actuator. Using beveled micropipettes filled with standard fish saline, extracellular microphonic potentials were recorded from hair cells in the inner ear of zebrafish embryos or larvae in response to $20,50,100$, and $200-\mathrm{Hz}$ stimulation. Saccular hair cells expressing green fluorescent protein of the transgenic zebrafish from 2 to 7 days post fertilization (dpf) were visualized and quantified using confocal microscopy. The otic vesicles' areas, otoliths' areas, and saccular hair cell count and density increased linearly with age and standard body length. Microphonic responses increased monotonically with stimulus intensity, stimulus frequency, and age of zebrafish. Microphonic threshold at $200 \mathrm{~Hz}$ gradually decreased with zebrafish age. The increases in microphonic response and sensitivity correlate with the increases in number and density of hair cells in the saccule. These results enhance our knowledge of early development of auditory function in zebrafish and provide the control data that can be
\end{abstract}

Correspondence to: Zhongmin Lu · Department of Biology · University of Miami $\cdot 1301$ Memorial Drive, Room 4, Coral Gables, FL 33146, USA. zlu@miami.edu, a.desmidt@umiami.edu used to evaluate hearing of young zebrafish morphants or mutants.

Keywords: hair cell, inner ear, otic vesicle, otolith organ, saccule, utricle

\section{INTRODUCTION}

The zebrafish (Danio rerio) has become an important model for biomedical research because of a combination of powerful genetics, excellent embryology, and exceptional in vivo visualization in one organism (Nüsslein-Volhard and Dahm 2002; Westerfield 2007). First, low cost and space requirements make the zebrafish an excellent organism to use for identifying defects in various biological systems using forward mutagenesis screens. Second, genetic manipulations such as morpholino knockdown and targeting induced local lesions in genomes work very well in the early development of zebrafish embryos. Third, external fertilization of eggs provides easy accessibility to embryos at all early developmental stages, and transparency of zebrafish embryos offers exceptional in vivo visualization of development of tissue/organs of interest. Finally, the zebrafish genome has been sequenced, and many human genes are conserved in zebrafish. Particularly, the zebrafish has been used as a unique vertebrate model for studying hearing and balance disorders (Nicolson et al. 1998; Ernest et al. 2000; Whitfield 2002; Söllner et al. 2004; Kappler et al. 2004; Nicolson 2005; Shen et al. 2008; Gleason et al. 2009; Phillips et al. 2011; Yariz et al. 2012), with its externally exposed hair cells of the lateral line being used for study in hair cell death 
and regeneration, ototoxicity, and drug screens (Chiu et al. 2008; López-Schier et al. 2004; Owens et al. 2009; Coffin et al. 2010; Buck et al. 2012).

Several studies have uncovered important time points in the zebrafish's inner ear auditory development as well. The zebrafish's otic vesicle begins to form at $16 \mathrm{~h}$ post fertilization (hpf) and gives rise to the main sensory components of the inner ear (Haddon and Lewis 1996). At $24 \mathrm{hpf}$, zebrafish have only two sensory maculae with otoliths that are located at the anterior and posterior ends of the otic vesicle, respectively. The anterior macula and otolith develop into the utricle, and the posterior macula and otolith become the saccule. The saccular otolith is oriented vertically with its medial side attaching to the saccular macula; the utricular otolith lies horizontally on the top of the utricular macula. The lagena does not appear until 11 days post fertilization (dpf). The inner ear of adult zebrafish has three pairs of otolith organs, each of which is composed of a calcareous otolith and a sensory epithelium covered with hair cells (Platt 1993; Bang et al. 2001; Bever and Fekete 2002). The utricle is located in the pars superior whereas the saccule and the lagena are in the pars inferior.

Hearing ability of fish has often been assessed with electrophysiological and behavioral approaches (see Higgs et al. 2006 for a review). Behavioral methods such as classical conditioning and food reward measure overall hearing ability of entire animals ( $\mathrm{Lu}$ et al. 1996; Cervi et al. 2012). Electrophysiological methods such as auditory brainstem recording and microphonic potential recording measure function of a portion of the auditory system (Kenyon et al. 1998; Lu and Tomchik 2002; Lu and Xu 2002; Sisneros 2007). The development of auditory function has been studied in several fish species that are juveniles and adults with a body length greater than $10 \mathrm{~mm}$ (Kenyon 1996; Higgs et al. 2002, 2003; Alderks and Sisneros 2011). Increasingly, zebrafish, particularly at early developmental stages younger than 1-week-old, have been used to investigate target genes that play important roles in hearing and balance because of the ease of using young zebrafish for live imaging and morpholino gene knockdown (Whitfield 2002; Nicolson 2005; Yariz et al. 2012). Although behavioral escape thresholds of zebrafish larvae have been reported (Zeddies and Fay 2005), hearing ability of such young zebrafish is still largely unknown.

Adult otophysan fishes such as zebrafish possess the Weberian ossicles connecting the swim bladder to the inner ear. It has been proposed that the inner ear of otophysans can be stimulated by particle motion via the direct pathway and by sound pressure via the indirect pathway, i.e., the swim bladder and the Weberian ossicles (see Popper and Fay 1993; Lu 2004 for reviews). The swim bladder in zebrafish starts to inflate at $5 \mathrm{dpf}$ but the Weberian ossicles do not exist for zebrafish younger than 1 week old (Higgs et al. 2003; Grande and Young 2004). Therefore, zebrafish during the first week of development are not likely sensitive to the pressure mode of sound because they lack the Weberian ossicles and/or the swim bladder to convey pressure stimulation to the inner ear. In this study, a stimulus probe was developed to directly stimulate the inner ear of zebrafish embryos or larvae (Corey et al. 2004; Starr et al. 2004), which simulates acoustic particle motion of sound. The microphonic potential method was successfully applied to young wild-type and mutant/ morphant zebrafish (Nicolson et al. 1998; Starr et al. 2004; Corey et al. 2004; Tanimoto et al. 2009; Trapani and Nicolson 2010), making it a quick and useful tool to assess hair cell function in the zebrafish model. In this study, we report the development of auditory function of zebrafish during the first week post fertilization by recording microphonic potentials from the inner ear and reveal the structural basis underlying the development of auditory function. Preliminary data of this study have been published in abstract form (Lu and DeSmidt 2012).

\section{MATERIALS AND METHODS}

\section{Zebrafish care and mounting}

Adult reproductive zebrafish (wild-type strain $\mathrm{AB}$ ) were purchased from the Zebrafish International Resource Center, Eugene, Oregon. SqET4 transgenic zebrafish with hair cells in the inner ear and lateral line expressing green fluorescent protein (GFP) were also used (Parinov et al. 2004; Go et al. 2010). Fish care and egg production were conducted as described by Nüsslein-Volhard and Dahm (2002) and Westerfield (2007) and used by Zamora and Lu (2013). Reproductive male and female zebrafish were normally kept in separate tanks and then placed together in the 3-1 tanks (6-10 zebrafish per tank) once every 2 weeks for breeding. Fertilized eggs were immediately collected and rinsed in E3 embryo medium containing $5.00 \mathrm{mM} \mathrm{NaCl}, 0.17 \mathrm{mM} \mathrm{KCl}$, $0.33 \mathrm{mM} \mathrm{CaCl} 2 \cdot 2 \mathrm{H}_{2} \mathrm{O}, 0.33 \mathrm{mM} \mathrm{MgSO}_{4} \cdot 7 \mathrm{H}_{2} \mathrm{O}$, and $\mathrm{dH}_{2} \mathrm{O}$. Zebrafish of 2 to $7 \mathrm{dpf}$ were used for the experiments in this study. The chorions of 2-dpf embryos were removed with forceps. The animal care protocol for all procedures used in this study was approved by the University of Miami Animal Care and Use Committee and complies with the guidelines of the National Institutes of Health.

The 35-mm MatTek Petri dish was modified to make a low profile recording chamber by cutting the wall down to 2 to $3 \mathrm{~mm}$ in height. Each zebrafish larva was embedded dorsal side up in $1.8 \%$ low melt agarose solution with $0.009 \%$ buffered MS-222 in the recording 
chamber. A small amount of phenol red with the final concentration of $0.045 \%$ was added to the solution to visualize agarose. The agarose covering the right side of the larva was scraped away with a 31.5-gauge syringe needle so that the right inner ear was exposed for positioning the stimulus probe and recording electrode. The top of the larva was then covered with a $0.25-\mathrm{ml}$ solution containing $116 \mathrm{mM} \mathrm{NaCl}, 2.9 \mathrm{mM} \mathrm{KCl}, 1.8 \mathrm{mM} \mathrm{CaCl}_{2}$, and $5.0 \mathrm{mM}$ Hepes ( $\mathrm{pH}=7.2$; Nagiel et al. 2009) to prevent the agarose from drying. The recording chamber was placed in a Petri dish holder that was temperature controlled at $\sim 28.5{ }^{\circ} \mathrm{C}$ (Model TC344B, Warner Instruments, Hamden, CT).

\section{Electrophysiology rig}

An electrophysiology rig was composed of a Zeiss Axioskop 2 FS plus fluorescence microscope with an

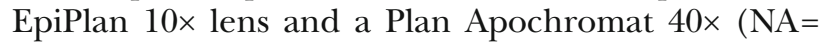
1.0) water immersion lens (working distance $=3.0 \mathrm{~mm}$ ) and BGFP, GFP, Texas Red, and DIC filters, Gibraltar stage, Zeiss CL 1500 ECO cold light source, and 63500 anti-vibration table with a Faraday cage (Technical Manufacturing Corporation, Peabody, MA). Other devices included a PCS-5000 threedimensional hydraulic micromanipulator (EXFO, Quebec, Canada) for holding a stimulus probe that connected to a piezoelectric actuator with its amplifier, MWS-1A manipulator (Narishige International USA, East Meadow, NY) for holding a ground electrode ( $\mathrm{Ag} / \mathrm{AgCl}_{2}$ electrode), Narishige MHW-3 three dimensional hydraulic micromanipulator for holding a recording electrode, P55 pre-amplifier (Grass Technologies, West Warwick, RI), Tektronics oscilloscope, system III for generating stimulation and data acquisition (Tucker-Davis Technologies, Alachua, FL), and PC with a 24-in. monitor.

Stimulus probe and piezoelectric actuator Stimulus probes with a tip size of $20 \mu \mathrm{m}$ in diameter were made from glass capillaries $(\mathrm{OD}=1.50 \mathrm{~mm}, \mathrm{ID}=0.84 \mathrm{~mm}$, World Precision Instruments (WPI), Sarasota, FL) using a P97 electrode puller (Sutter Instrument Company, Novato, CA) and Narishige MF-900 microforge. The probe displacement driven by a piezoelectric actuator (piezosystem jena, Inc., Hopedale, MA) was first calibrated at the selected frequencies under the Zeiss Axioskop microscope with an Inline1000 1GB highspeed camera (Fastec Imaging, San Diego, CA). The displacement of the stimulus probe was always set at $5.8 \mu \mathrm{m}$ during the experiments unless otherwise specified in the text. The probe tip was placed against the skin at the posterior end of the otic vesicle (pointing to the saccular otolith) and provided linear oscillatory motion along an axis $20^{\circ}$ off the longitudinal axis of the fish body (Corey et al. 2004; Starr et al. 2004). The parameters such as size, angle, and location of the stimulus probe affecting microphonic responses were kept constant for all recordings reported herein.

Recording and reference electrodes Recording electrodes were sharp micropipettes made from WPI glass capillaries $(\mathrm{OD}=1.50 \mathrm{~mm}, \mathrm{ID}=1.12 \mathrm{~mm})$ with the Sutter P97 microelectrode puller. They were filled with standard fish saline solution containing $129.6 \mathrm{mM} \mathrm{NaCl}, 2.7 \mathrm{mM} \mathrm{KCl}$, and $1.8 \mathrm{mM} \mathrm{CaCl}_{2}$ $(\mathrm{pH}=7.2)$ and had resistance in a range from 20 to $50 \mathrm{M} \Omega$. To facilitate the penetration of the electrode tip into the otic vesicle of a zebrafish embryo or larva, each recording electrode tip was sharpened with its resistance down to about 4 to $6 \mathrm{M} \Omega$ using a Sutter BV10-E microelectrode beveler. The beveled microelectrode tip was verified for sharpness with the Narishige MF-900 microforge. The recording electrode was mounted in a Warner half-cell holder secured by a Narishige micromanipulator, and the electrode tip was advanced to penetrate the wall of the otic vesicle of the zebrafish (see Fig. 1). The half-cell electrode holder was connected to a Grass HZP high impedance headstage and then the Grass P55C pre-amplifier. An $\mathrm{Ag} / \mathrm{AgCl}$ reference electrode was placed into the solution in the recording chamber. For consistency, the recording electrode tip was always pointing to the center of the saccular otolith and positioned about $5 \mu \mathrm{m}$ away from the edge of the otolith.

TDT system III A TDT system III setup previously used for auditory brainstem recording ( $\mathrm{Lu}$ and Tomchik 2002; $\mathrm{Lu}$ and $\mathrm{Xu}$ 2002) was modified for microphonic potential recording from the inner ear in this study. The TDT hardware included two RP2.1 processors and two PA-5 programmable attenuators. Sine waves with the peak-to-trough amplitude of $\pm 10 \mathrm{~V}$ at 20,50 , 100 , and $200 \mathrm{~Hz}$ were synthesized using SigGen software. Each stimulus signal at 20, 50 , and $100 \mathrm{~Hz}$ had four stimulus cycles with pre- and post-signal periods of $20 \mathrm{~ms}$, which yielded stimulus durations of 240, 120, and $80 \mathrm{~ms}$, respectively. The $200-\mathrm{Hz}$ signal had a duration of $80 \mathrm{~ms}$ containing 8 cycles with preand post-signal periods of $20 \mathrm{~ms}$. The amplitude of stimuli was set at desired levels with the PA-5 programmable attenuators. Stimulus signals synthesized by SigGen were loaded into the TDT BioSig software, sent out to the PA-5 programmable attenuators, led to the piezoelectric actuator amplifier, and passed to the actuator to drive the stimulus probe.

Data acquisition and analysis Microphonic potential responses were amplified 1,000× and filtered between 0.1 and $3,000 \mathrm{~Hz}$ by the Grass $\mathrm{P} 55 \mathrm{C}$ pre-amplifier, 

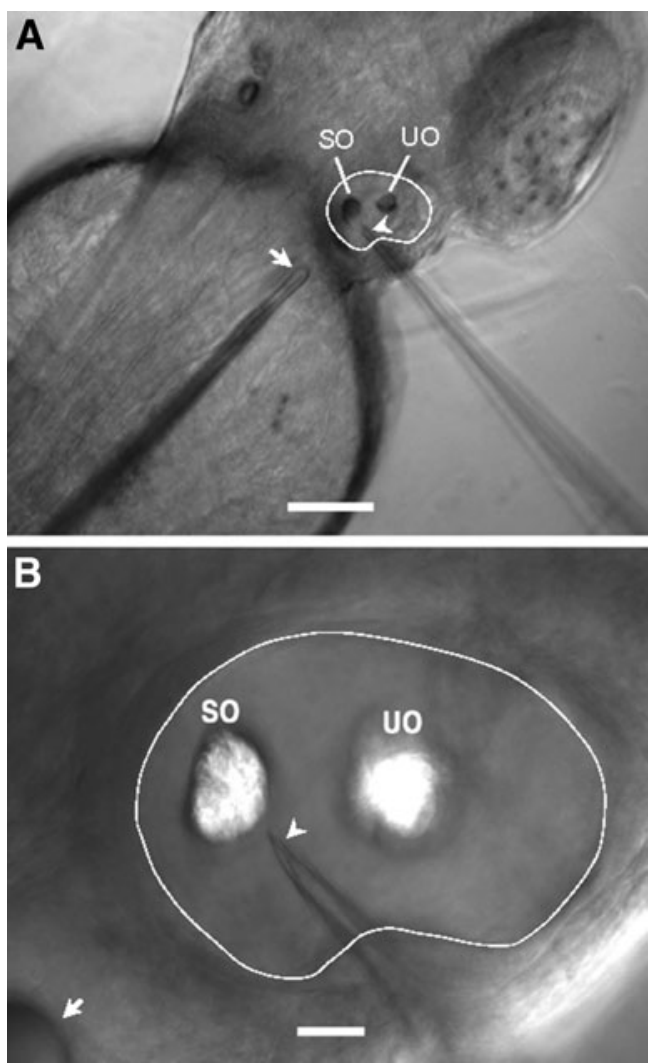

FIG. 1. A Image of a 2-dpf zebrafish embedded in agarose from the dorsal view, showing the right otic vesicle outlined by a white line, the stimulus probe indicated by the arrow, and the beveled recording micropipette marked by the arrowhead. SO saccular otolith, UO utricular otolith. Scale bar=100 $\mu \mathrm{m}$. For illustration purposes, the embryo was treated in $0.003 \%$ 1-phenyl-2-thiourea (PTU) in E3 to suppress pigment formation in order to have a better view of the otic vesicle and tips of the stimulus probe and recording micropipette. B Enlarged image of the right otic vesicle shown in $\mathbf{A}$ with $\mathrm{SO}$ and $\mathrm{UO}$, the stimulus probe (arrow), and the beveled tip (arrowhead) of the recording micropipette. Scale bar $=20 \mu \mathrm{m}$.

recorded at a sampling rate of $25 \mathrm{kHz}$, and averaged 200 times in order to extract the microphonic signals from the background noise using TDT BioSig. They were displayed in both time and frequency domains. The amplitude of microphonic responses (RMS) was measured in time domain, and the dominant frequency of microphonic response, i.e., doubling of the stimulus frequency $(2 \mathrm{~F})$, was verified in Fast Fourier Transform (FFT) plots. At a given stimulus frequency, microphonic responses were recorded as stimulus displacement gradually decreased at a step of about $3 \mathrm{~dB}$ until a threshold was reached. Threshold was defined as the lowest stimulus displacement that generated a microphonic response in the FFT plot with the peak at $2 \mathrm{~F}$ that was just higher than the background noise level at $2 \mathrm{~F}$. Threshold was determined using the TDT BioSig software.

\section{Fluorescent labeling with FM1-43X}

The recording microelectrode tip was first filled with 1mM FM1-43X (Invitrogen, Grand Island, NY) in standard fish saline, and the rest of the microelectrode was then back filled with the fish saline alone. After the microelectrode tip penetrated into the otic vesicle, the FM1-43X solution was pressure injected into the otic vesicle with a $10-\mathrm{ml}$ syringe connected to the pressure port of the electrode holder. The injection was monitored under the Zeiss Axioskop microscope with the 40× water immersion objective lens and a Texas Red filter set in order to verify hair cell uptake of the dye, which is known to selectively and rapidly label sensory hair cells and then block their responses, presumably by entering mechanotransduction ion channels (Nishikawa and Sasaki 1996; Nicolson et al. 1998; Gale et al. 2001; Meyers et al. 2003). FM1-43X was used as a control to rule out stimulus artifact as shown in Fig. 3A, B.

\section{Quantification of the otic vesicle area, otolith area, and hair cells}

Chorions of unhatched embryos were manually removed with forceps. Zebrafish embryos/larvae were anesthetized in $0.01 \%$ buffered MS-222 ( $w / v$, ethyl 3aminobenzoate methanesulfonate salt, Sigma-Aldrich) until the movement of fish ceased. After they were laterally positioned on a 35-mm MatTek dish, the otic vesicles and otoliths of fish were imaged at $225 \times$ using a SteREO Discovery V20 fluorescence microscope with an AxioCam MRm digital camera and AxioVision software 4.8 (Zeiss, Thornwood, NY). The laterally viewed areas of otic vesicles and otoliths were measured with Image J (National Institute of Mental Health, Bethesda, MD).

To quantify saccular hair cells, SqET4 transgenic zebrafish were fixed in $4 \%$ fresh paraformaldehyde at $4{ }^{\circ} \mathrm{C}$ for $2 \mathrm{~h}$ then rinsed in PBS 3 times for 10 min each. To visualize the entire saccular epithelium, the saccule otolith was dissolved in $0.5 \%$ Triton X-100 (SigmaAldrich, St. Louis, MO) for up to $2 \mathrm{~h}$ at room temperature. All zebrafish were subsequently positioned laterally in Vectashield anti-fading solution (Vector Laboratories, Burlingame, CA) in 35-mm MatTek dishes. A $z$ stack of images of GFP-labeled hair cells in the saccule were taken and then $3 \mathrm{D}$ reconstructed using a C-1 confocal unit with the $488 \mathrm{~nm}$ laser line and a TE2000 inverted microscope (Nikon, Melville, NY). The number of saccular hair cells was counted, and the area of the saccular epithelium was measured using Nikon NIS-Elements imaging software (see Zamora and Lu 2013). 


\section{Statistics}

One-way ANOVAs (Microsoft Excel 2007) were used to find out if there was a significant difference in microphonic response among different stimulus frequencies, stimulus levels, and fish ages. One-way ANOVAs were also used to determine any significant difference in saccular hair cell count and density among zebrafish at different ages, and to test the significance of regression of selected parameters such as otocyst area, otolith area, and hair cell count and density on age or standard length. Furthermore, Student's t-test was also used to determine any significant difference in hair cell count between wild-type $\mathrm{AB}$ and SqET4 transgenic zebrafish. In this study, the significant level was set at 0.05 , and data were represented as means \pm 1 SEM.

\section{RESULTS}

\section{Ear microphonic potential}

Microphonic potentials were recorded from the otic vesicles of zebrafish from 2 to $7 \mathrm{dpf}$. Figure 1 shows the right otic vesicle of a 2-dpf embryo embedded in agarose with a stimulus probe tip positioned against the body adjacent to the posterior end of the otic vesicle and a beveled micropipette tip impaled into the otic vesicle, pointing to the saccular otolith, for microphonic potential recording. A characteristic feature of microphonic response from hair cells in the inner ear of zebrafish and other fishes is that its frequency is twice the stimulus frequency, as illustrated by a representative microphonic waveform plotted in time and frequency domains (Fig. 2).

Two control experiments were conducted to distinguish microphonic potential response from stimulus artifact. In the first experiment, FM1-43X injected into the otic vesicle completely wiped out any microphonic response from hair cells in the inner ear at the three stimulus frequencies tested (Fig. 3A). Note that after the FM-1-43X injection a small residue waveform present at $100 \mathrm{~Hz}$ as shown in Fig. 3A was likely due to stimulus artifact because no peak was observed at $2 \mathrm{~F}$ in a FFT plot of this waveform (not shown). Hair cells in saccular and utricular maculae as well as anterior, lateral, and posterior cristae in the three semicircular canals were labeled with FM1-43X after the injection (see Fig. 3B).

In the second experiment, microphonic responses were recorded from a larva before and after saccular and utricular otoliths were displaced (Fig. 3C, D). The recording electrode tip was used to push the otoliths away from their original positions, and the electrode tip was then moved back to its recording position before the otolith displacement. The displacement of the saccular otolith alone reduced the microphonic amplitude to $23 \%$ at $200 \mathrm{~Hz}$. The microphonic response dropped to 6-7\% after both saccular and utricular otoliths were displaced.

\section{Development of frequency and intensity response}

To investigate effects of stimulus frequency on microphonic response of zebrafish, iso-level frequency responses were recorded at 20, 50, 100, and $200 \mathrm{~Hz}$ (see Fig. 4A). Microphonic responses were robustly recorded at these stimulus frequencies, showing the doubling of the stimulus frequency. At a given stimulus displacement, i.e., $5.8 \mu \mathrm{m}$, the amplitude of microphonic potentials of zebrafish at 3, 5, and $7 \mathrm{dpf}$ significantly increased as stimulus frequency increased from 20 to $200 \mathrm{~Hz}$ (Fig. 4B, one-way ANOVA, $F_{(3,186)}=$ $18.75, p<0.0001)$. In addition, at a given stimulus frequency, i.e., $200 \mathrm{~Hz}$, we observed the microphonic response in both time and frequency domains increased with stimulus displacement (Fig. 5A). At $200 \mathrm{~Hz}$, significant increases in microphonic response were found as stimulus displacement increased in a range from 34 to $11,592 \mathrm{~nm}$ (Fig. 5B, one-way ANOVA, $\left.F_{(14,113)}=27.24, p<0.0001\right)$. The increase in microphonic response with stimulus displacement is consistent among zebrafish at different ages.

\section{Development of inner ear morphology}

We then investigated morphological changes of the otic vesicle of zebrafish from 2 to $7 \mathrm{dpf}$. During the first-week of zebrafish development, the otic vesicle area, otolith area, number of saccular hair cells, and density of saccular hair cells increased linearly with age and standard body length (Fig. 6). From the lateral view, the saccular epithelium is calabash shaped with the anterior portion smaller than the posterior, and has the following averages of sensory hair cell counts: $28.1 \pm 5.0$ $(N=14), 49.9 \pm 3.2(N=8), 65.4 \pm 7.0 \quad(N=13), 80.2 \pm 5.6(N$ $=12), 84.0 \pm 3.8(N=11)$, and 92.2 $\pm 5.4(N=11)$ for $2,3,4$, 5, 6, and 7-dpf zebrafish, respectively (Fig. 6B). Although the shape of the saccular epithelium did not change, number and density of saccular hair cells increased significantly with age (one-way ANOVAs; $F_{(1,68)}=566.55$, $p<0.0001$ for cell count; $F_{(1,68)}=47.89, p<0.0001$ for cell density). The average increase in saccular hair cells was 13 hair cells per day whereas the average increase in saccular hair cell density was 2 cells $/ 1,000 \mu^{2}$ per day.

\section{Development of auditory function}

Microphonic responses were recorded from the inner ear of zebrafish from 2 to $7 \mathrm{dpf}$ in response to $200-\mathrm{Hz}$ stimuli at $5.8 \mu \mathrm{m}$ in displacement. During the early development of zebrafish, micro- 
A

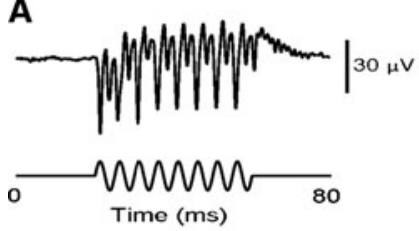

C

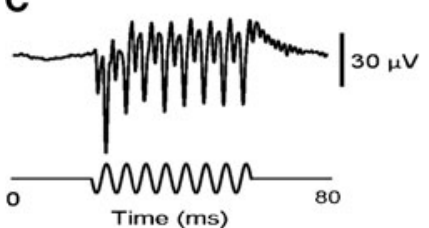

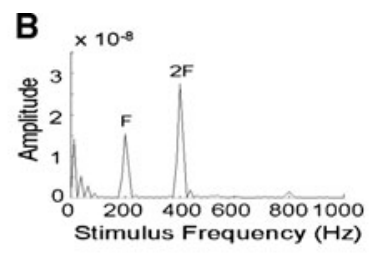

D

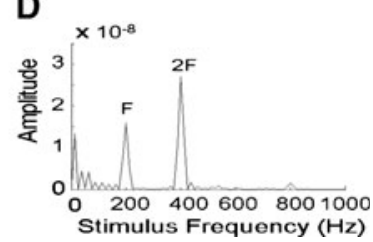

FIG. 2. Microphonic waveforms plotted in time domain (left column) and frequency domain (right column) for a 3-dpf larva in response to $200-\mathrm{Hz}$ stimuli at $5.8-\mu \mathrm{m}$ displacement with different start phases $\left(0^{\circ}\right.$ in $\mathbf{A}$ and $\mathbf{B}, 180^{\circ}$ in $\mathbf{C}$ and $\left.\mathbf{D}\right)$. Each microphonic waveform was averaged over 200 stimulus presentations. In A and C, top traces are microphonic responses whereas lower traces are stimulus waveforms with a start phase shift of $180^{\circ}$. In $\mathbf{B}$ and $\mathbf{D}$, each FFT plot shows a minor peak at $200 \mathrm{~Hz}$, the stimulus frequency (F) and a major peak at $400 \mathrm{~Hz}$, twice the stimulus frequency (2F).

phonic response increased significantly with age (Fig. 7A, one-way ANOVA, $F_{(4,59)}=9.33, p<0.0001$ ). This increase in microphonic response correlated well with the number and density of hair cells in the saccule (Fig. 7B, C).

A
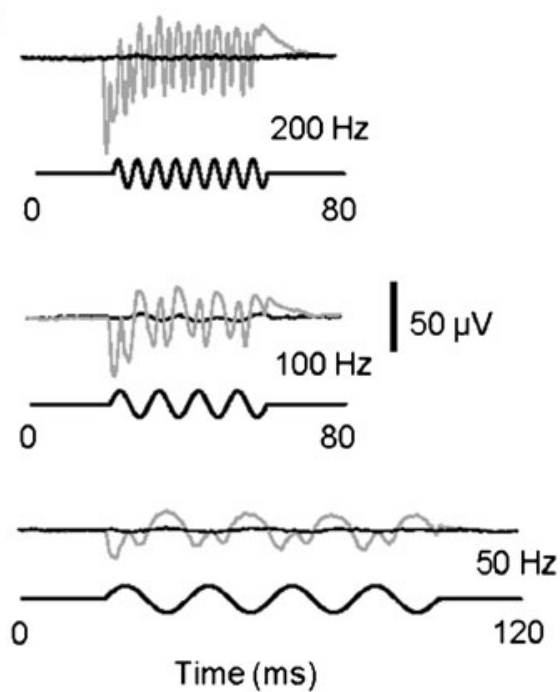

B

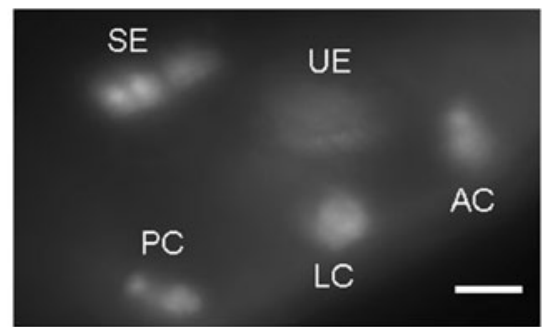

C

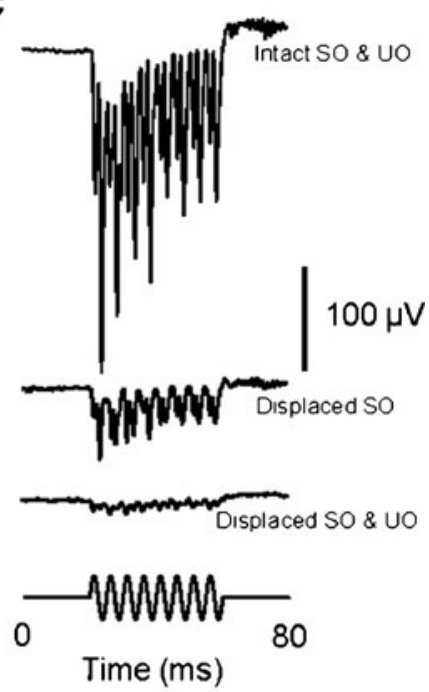

D

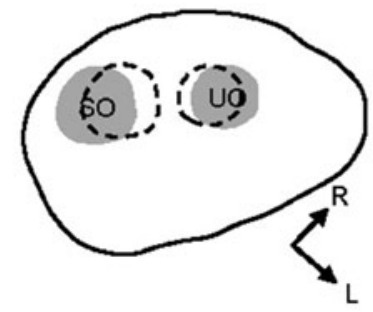

In addition, we investigated the development of auditory sensitivity of hair cells in the otic vesicle of zebrafish from 2 to $7 \mathrm{dpf}$ by measuring microphonic thresholds at $200 \mathrm{~Hz}$. Figure 5A shows microphonic waveforms for a larva in response to $200-\mathrm{Hz}$ stimuli at a series of stimulus displacements with a threshold of $310 \mathrm{~nm}$. During the early development of zebrafish, microphonic threshold gradually and significantly decreased with age (Fig. 7D, one-way ANOVA, $F_{(4,57)}=7.85$, $p<0.0001)$. The decrease in threshold appeared to correlate with the increases in number and density of hair cells in the saccule (Fig. 7E, F).

In order to determine whether or not SqET4 transgenic zebrafish have the same number of hair cells as wild-type zebrafish, we counted number of hair cells in lateral line neuromasts and found no significant difference in number of hair cells per neuromast between wild-type zebrafish $(11.6 \pm 2.0, N=4)$ and SqET4 transgenic zebrafish $(11.5 \pm 1.8, N=4)$ (Student's $t$-test, $t_{0.05(2), 6}=0.89, p=0.44$, see Fig. 8 ).

\section{DISCUSSION}

In this study, we assessed auditory function of hair cells in the inner ear of young zebrafish using microphonic potential recording. This is the first study to report 
A
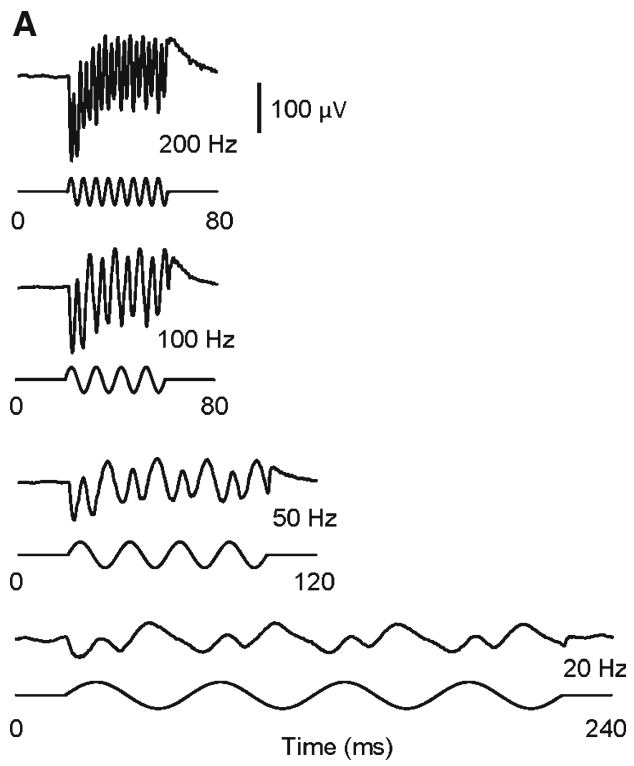

B

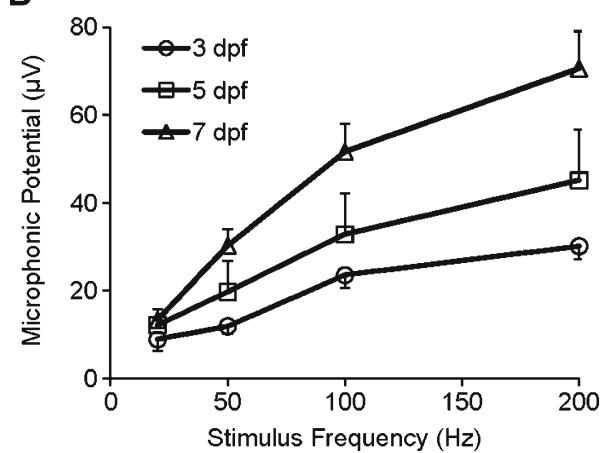

FIG. 4. A Microphonic waveforms of a zebrafish in response to stimuli at different frequencies of $20,50,100$, and $200 \mathrm{~Hz}$ (from bottom to top). B Microphonic amplitude versus stimulus frequency functions for zebrafish at three ages $(N=19,7$, and 9 for 3, 5, and 7dpf zebrafish, respectively). The displacement of the stimulus probe was fixed at $5.8 \mu \mathrm{m}$ in $\mathbf{A}$ and $\mathbf{B}$.

ontogeny of hearing of any fish during the first week post fertilization. This is also the first study on the development of particle motion sensitivity in teleosts. As shown in this paper, microphonic potentials can be robustly recorded from zebrafish of 2 to $7 \mathrm{dpf}$. Like microphonic responses that were previously reported in adult and juvenile fish and amphibians, microphonic waveforms recorded from the inner ear of zebrafish embryos/larvae have a characteristic feature of doubling the stimulus frequency, due to groups of hair cells in the inner ear that are oriented opposing to or opposite each other (Flock 1965; Furukawa et al. 1972; Fay and Popper 1974; Corey and Hudspeth 1983; Sisneros 2007), making them distinguishable from stimulus artifact or background noise. Results of this study demonstrate that microphon- ic recording can be a quick and reliable physiological method to assess a difference in auditory function between control zebrafish and morphants/mutants during the first week of development.

\section{Factors affecting the microphonic potential recording}

To prevent fish movement during the recording, MS222 was added to the agarose. The $0.009 \%$ MS-222 concentration used in this study can sufficiently anesthetize one-week old zebrafish. Palmer and Mensinger (2004) reported that MS-222 concentrations lower than $0.01 \%$ did not significantly reduce either spontaneous or evoked responses of sensory fibers innervating hair cells in the anterior lateral line of the toadfish. Although they did observe suppression of lateral line afferent response at higher MS-222 concentrations, it is not known whether the suppressive effects result from MS-222 action on hair cells, sensory afferents, or both. Unlike lateral line hair cells, the hair cells in the otocyst that we recorded from were not directly exposed to MS-222 solution. However, whether or not the $0.009 \%$ MS-222 concentration we used suppresses microphonic response remains to be investigated.

Loudspeakers or mechanical shakers have traditionally been used to provide acoustic stimulation for fish hearing research (Fay 1984; Lu and Fay 1996; Lu et al. 1996; Lu and Tomchik 2002; Tomchik and Lu 2006; Lu et al. 2010). Particularly, Fay's shaker apparatus was used to accelerate the whole fish, resulting in acceleration of the inner ear, to simulate underwater acoustic particle motion (Fay 1984; Lu et al. 1996). In this study, we adapted a stimulus probe from Corey et al. (2004) and Starr et al. (2004) to provide focal stimulation directly to the inner ear of zebrafish embryos or larvae instead of accelerating the entire fish body. The oscillatory motion of the probe tip caused the vibration of the posterior wall of the otic vesicle, leading to auditory transduction of hair cells in the inner ear. Since the probe displacement is easy to measure, the displacement rather than velocity or acceleration was chosen as an independent variable. The parameters such as size, angle and location of the stimulus probe affecting microphonic responses were kept constant for all recordings reported herein.

\section{Contributors to microphonic responses}

Hair cells in the inner ear and the lateral line of frogs and fish are oriented in various directions. They are directional sensors, having the maximal response along their morphological polarizations (Hudspeth and Corey 1977; Lu and Popper 1998; Lu and Popper 
A
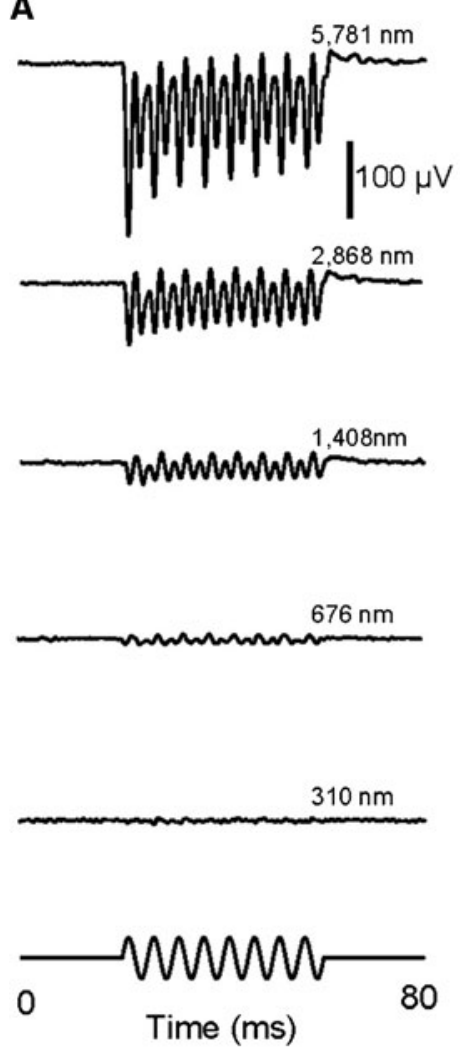

B

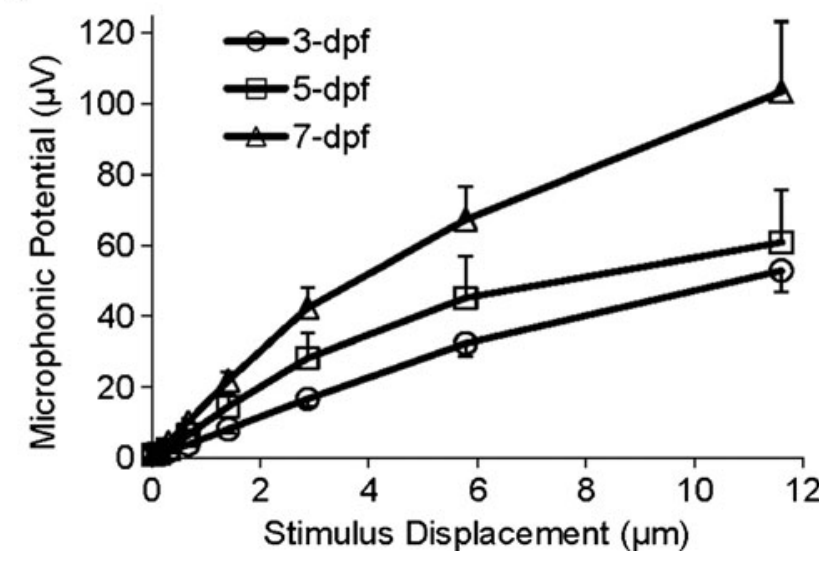

FIG. 5. A Microphonic waveforms (left column) and FFT plots (right column) of a zebrafish in response to $200-\mathrm{Hz}$ stimuli from small to large displacements indicated in the figure. In each FFT plot, the peak at the stimulus frequency, $200 \mathrm{~Hz}$ is marked by $F$ whereas the peak at twice the stimulus frequency is marked by $2 F$. Note that for the bottom two FFT plots, the $Y$ scales are decreased $100 \times$ compared with the top three plots in order to display the peaks at $2 \mathrm{~F}$. B Microphonic amplitude versus stimulus level functions of zebrafish at 3,5 , and $7 \mathrm{dpf}$ in response to $200-\mathrm{Hz}$ stimuli ( $N=10$ each age).

2001). Thus, stimulus direction or axis affects hair cell response. Larval zebrafish have the standard hair cell orientation pattern as described by Popper and Coombs (1982). For 5-dpf zebrafish, the hair cells in the anterior part of the saccular epithelium are oriented around the longitudinal axis of the fish whereas the hair cells in the posterior portion are oriented along the dorsoventral axis (Haddon et al. 1999). Since the stimulus probe used in the present study was positioned at a $20^{\circ}$ angle to the horizontal plane, it more effectively activated the hair cells in the rostral portion of the saccular epithelium than the hair cells in the caudal portion.

At the first week post fertilization, both saccular and utricular hair cells share the fluid in the otic vesicle with no membrane separating them. For the horizontally positioned utricular epithelium, the hair cells in the central portion radiate out from the epithelium's medial edge whereas the hair cells in the lateral peripheral rim point to the center of the epithelium (Haddon et al. 1999). The stimuli provided in this study would affect only a small portion of the utricular hair cells that are oriented along the stimulus axis. However, most utricular hair cells were less likely to be activated by the stimulus used in this study because they are oriented approximately perpendicular to the stimulus axis. In addition, the utricle is located farther away from the stimulus probe than the saccule, resulting in weaker stimulation to the utricle than the saccule. Thus, we propose that the recorded microphonic responses mainly result from saccular hair cells whereas utricular hair cells contribute to the microphonic response to a much lesser extent. This interpretation is supported by our results of microphonic responses from zebrafish before and after the displacement of the saccular otolith alone and both saccular and utricular otoliths (see Fig. 3C, D).

Riley and Moorman (2000) demonstrated that the utricle is critical for vestibular function and survival in zebrafish using monolith mutants with six otolith phenotypes. They showed that zebrafish mutants (S-S) lacking both utricular otoliths but having intact saccular otoliths had no counterrotation of the eyes, swam circularly, and could not survive to adulthood likely due to starvation caused by loss of balance; whereas zebrafish mutants (U-U, U-S, S-US, or U-US) having at least a utricular otolith at one side had normal vestibular function. Therefore, the utricle plays an important role in balance and the saccule and lagena are not necessary for balance in zebrafish. However, it is still unclear what roles the saccule and lagena play in zebrafish hearing.

\section{Development of structure and function of the inner ear}

In order to understand the structural basis underlying functional development of the inner ear of zebrafish, we measured several key parameters such as the otic vesicle area, otolith area, saccular hair cell count, and 
saccular hair cell density and plotted them against age as well as standard body length. Our results show that these parameters appear to correlate better with age
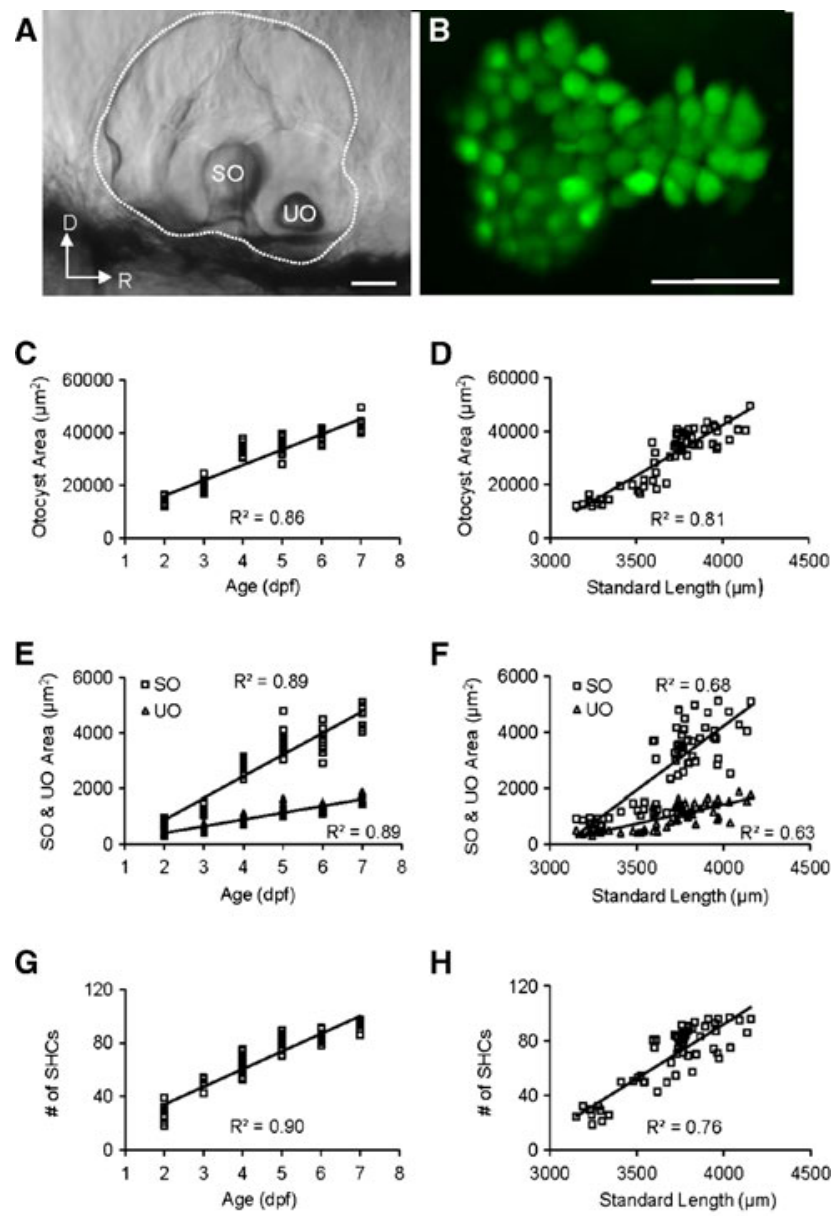

H

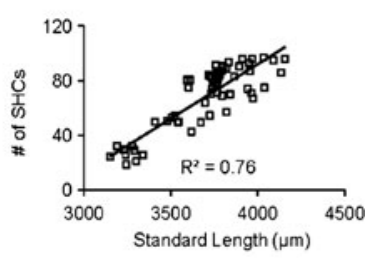

I

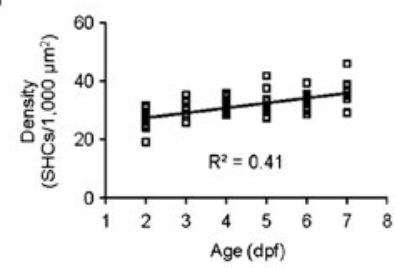

$\mathbf{J}$

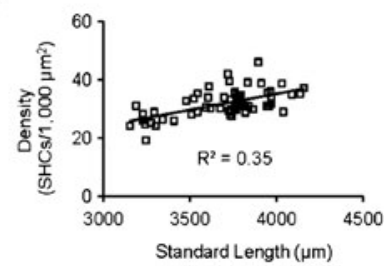

FIG. 6. A Image of the otic vesicle (indicated by dots) with $\mathrm{SO}$ and UO of a 3-dpf zebrafish from the lateral view. $D$ dorsal, $R$ rostral. Scale bar $=50 \mu \mathrm{m}$. B Confocal image of saccular hair cell bodies expressing green fluorescent protein of the zebrafish shown in $\mathbf{A}$ after the SO was dissolved with $0.5 \%$ Triton X-100. The image in $\mathbf{B}$ has the same orientation as the image in A. Scale bar $=25 \mu \mathrm{m}$. C Regression of the otocyst area on age $\left(F_{(1,59)}=355.95, p<0.0001\right)$. D Regression of the otocyst area on standard length $\left(\mathrm{SL}, F_{(1,59)}=255.00, p<0.0001\right)$. $\mathbf{E}$ Regression of the SO and $U \mathrm{O}$ area on age $\left(\mathrm{SO}, F_{(1,59)}=460.57, p<\right.$ 0.0001; UO, $\left.F_{(1,59)}=465.48, p<0.0001\right)$. F Regression of the $\mathrm{SO}$ and $\mathrm{UO}$ area on SL (SO, $F_{(1,59)}=128.09, p<0.0001 ; \mathrm{UO}, F_{(1,59)}=99.57, p<$ 0.0001). G Regression of number of saccular hair cells (SHCs) on age $\left(F_{(1,68)}=566.55, p<0.0001\right)$. $\mathbf{H}$ Regression of number of SHCs on SL $\left(F_{(1,59)}=128.90, p<0.0001\right)$. I Regression of SHC density (SHCs/ $\left.1,000 \mu \mathrm{m}^{2}\right)$ on age $\left(F_{(1,68)}=47.89, p<0.0001\right)$. J Regression of SHC density $\left(\mathrm{SHCs} / 1,000 \mu \mathrm{m}^{2}\right)$ on $\mathrm{SL}\left(F_{(1,59)}=33.83, p<0.0001\right)$. than standard body length (see Fig. 6). In this study, we were particularly interested in the relationship between the inner ear morphology and age during the first week of development in zebrafish. We counted numbers of saccular hair cells using the SqET4 transgenic zebrafish, which is known to express GFP in hair cells in the inner ear as well as the lateral line (Parinov et al. 2004; Go et al. 2010). The SqET4 transgenics used in the present study represent $\mathrm{Tg}$ (atp2b1a: GFP), i.e., GFP expression in hair cells is under the control of the atp2bla gene that functions as a $\mathrm{Ca}^{2+}$ exporter (Go et al. 2010). Because GFP starts to express during the early formation of hair cells of SqET4 zebrafish, GFPlabeled hair cells include all of the hair cells with and without ciliary bundles. Haddon and Lewis (1996) reported number of hair cells by counting phallodinlabeled ciliary bundles, excluding the hair cells that had not yet developed ciliary bundles. Therefore, our saccular hair cell counts are higher than those reported by Haddon and Lewis (1996).

Previous studies using auditory brainstem recording have shown that the pressure sensitive frequency range of adult zebrafish is between 500 and $800 \mathrm{~Hz}$ (Higgs et al. 2003; Cervi et al. 2012). In this study, we used stimulus frequencies in a lower range from 20 to $200 \mathrm{~Hz}$ because the zebrafish embryos/larvae that we recorded from were likely more sensitive to lower frequencies due to the fact that they had not yet developed the Weberian ossicles, an auditory accessory known to increase auditory sensitivity at high frequencies. The saccule and utricle of zebrafish of one week old or younger are only "motion sensitive" via a direct stimulus pathway as described by Popper and Fay (2011), and the inner ear of zebrafish is not yet pressure sensitive until the initial formation of the Weberian ossicles at about $20 \mathrm{dpf}$ (Grande and Young 2004). The stimulus probe we used is thought to provide acoustic particle motion via direct inertial stimulation to hair cells in the otocyst.

Compared with mammals (see a review by Rübsamen and Lippe 1998), the zebrafish is a unique model for the study of early development of hearing and balance in vertebrates because the inner ear of zebrafish embryos is easily accessible for live imaging, physiological recording, and genetic manipulation (Waterman and Bell 1984; Haddon and Lewis 1996; Nicolson et al. 1998; Bever and Fekete 2002; Whitfield 2002; Nicolson 2005; Zeddies and Fay 2005; Tanimoto et al. 2011). Previous studies have reported on the development of auditory sensitivity in a few juvenile and adult teleosts using various physiological methods (Corwin 1983; Kenyon 1996; Higgs et al. 2003; Sisneros and Bass 2005; Vasconcelos and Ladich 2008; Alderks and Sisneros 2011; Lechner et al. 2012). To our knowledge, the present study is the first investigation of the early development of particle motion sensitivity in any fish, particularly in the first 
A

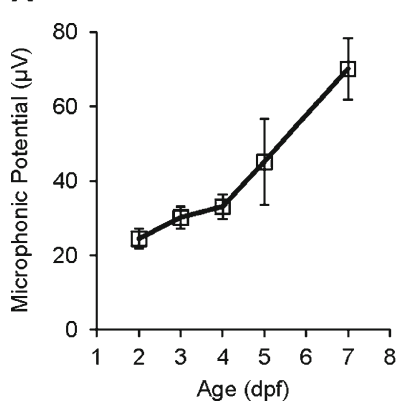

B

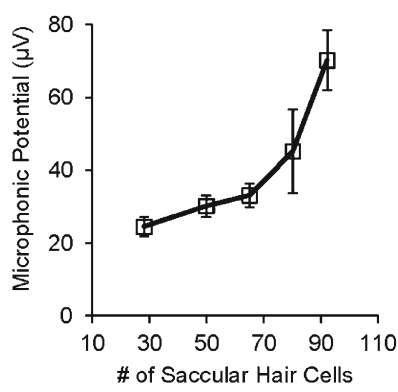

C:

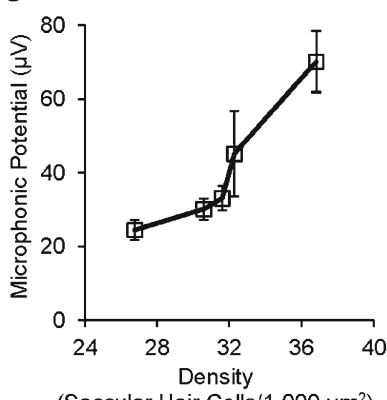

D

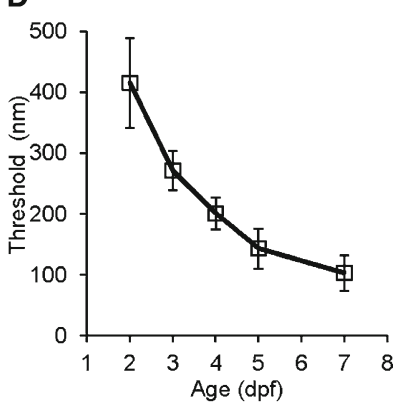

E
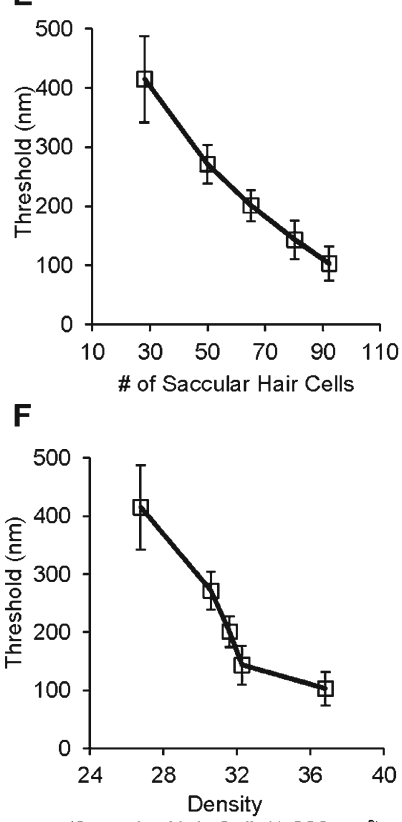

(Saccular Hair Cells/1,000 $\mu \mathrm{m}^{2}$ )

anatomical and physiological changes in the inner ear. Thus, results from the present study along with those from Zeddies and Fay (2005) indicate that the particle motion input to the inner ear that can trigger the escape behavior appears to increase as zebrafish larvae grow.

Does hearing sensitivity increase with age/size in zebrafish? There are some mixed results from reported studies, and there is still no clear answer. Previous studies have reported that auditory pressure sensitivity increases with size or age of otophysans and non-otophysans with the exception of Higgs et al. (2003) who found no change in auditory pressure sensitivity for young zebrafish from 10 to $45 \mathrm{~mm}$ in total length (Kenyon 1996; Higgs et al. 2003; Sisneros and Bass 2005; Vasconcelos and Ladich 2008; Alderks and Sisneros 2011; Lechner et al. 2012). In contrast to the results from Higgs et al. (2003), hearing sensitivity of the African bullhead catfish, an otophysan, increases with the development of Weberian ossicles (Lechner et al. 2012). Caution should be taken when comparing our results with the results of Higgs et al. (2003). First, the zebrafish used in this study were

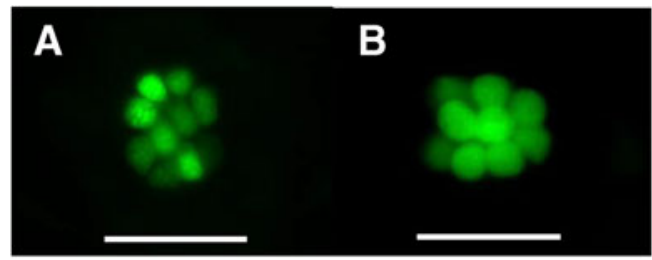

FIG. 7. A Microphonic potential as a function of zebrafish age. B Microphonic potential as a function of the number of saccular hair cells. C Microphonic potential as a function of the density of saccular hair cells. In $\mathbf{A}$ to $\mathbf{C}$, microphonic responses (RMS) were obtained in response to $200-\mathrm{Hz}$ stimuli at $5.8-\mu \mathrm{m}$ displacement. D Threshold as a function of zebrafish age. E Threshold as a function of number of saccular hair cells. $\mathbf{F}$ Threshold as a function of the density of saccular hair cells. In $\mathbf{D}$ to $\mathbf{F}$, thresholds were determined from FFT plots using the TDT BioSig software; stimulus frequency $=200 \mathrm{~Hz} . \mathrm{N}=14,20,10,10$, and 10 for age groups in $\mathbf{A}$ and $\mathbf{D}$, for hair cell groups in $\mathbf{B}$ and $\mathbf{E}$, and for cell density groups in $\mathbf{C}$ and $\mathbf{F}$.

week post fertilization, differing from most previous studies that reported on the development of auditory pressure sensitivity. Zeddies and Fay (2005) reported behavioral escape thresholds measured in both pressure and acceleration of larval zebrafish from 4 to 26 dpf in response to vertical stimulation generated by the shaker apparatus. They found that the escape response was not observed until 5-dpf and the behavioral escape thresholds remained the same as zebrafish larvae grew older. In this study, we reported absolute particle motion thresholds and showed increases in auditory sensitivity with age during the first week of development of zebrafish, a period of rapid

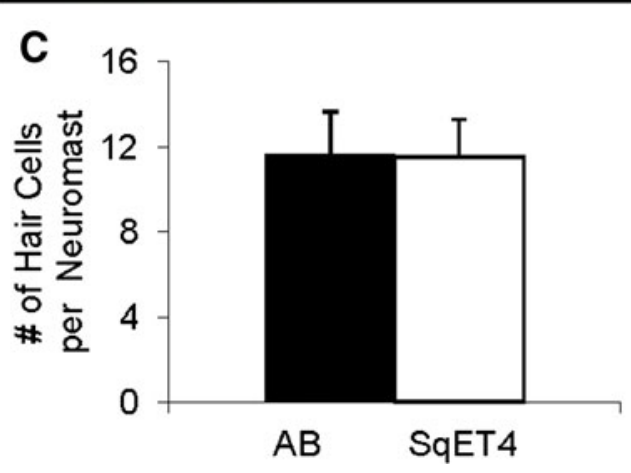

FIG. 8. A A representative lateral line neuromast of a 6-dpf wildtype $A B$ zebrafish, showing hair cell nuclei labeled with a vital fluorescent dye Yo-Pro-1 (green). The zebrafish was placed in 3- $\mu \mathrm{M}$ Yo-Pro-1 solution for $10 \mathrm{~min}$. Yo-Pro-1 is known to label nuclei of lateral line hair cells (Zamora and Lu 2013). B A representative lateral line neuromast of a 6-dpf SqET4 zebrafish, showing hair cell bodies labeled with GFP. Scale bars in A and B are $50 \mu \mathrm{m}$. C Histograms of average hair cell counts per neuromast with standard errors of means for wild-type AB and SqET4 transgenic zebrafish. We determined number of hair cells per neuromast by counting Yo-Pro-1 labeled nuclei of hair cells of AB zebrafish and GFP-labeled hair cells of SqET4 transgenic zebrafish, respectively. For each fish, data were collected based on hair cell counts in posterior neuromasts P1, P5, and P9. Nomenclature of posterior neuromasts was adapted from Metcalfe et al. (1985). 
much younger than those used in Higgs' study. In our study, we investigate the early development of the otic vesicle from the end of embryonic development (i.e., 2 $\mathrm{dpf}$ ) to very early postembryonic development (3 to 7 dpf). At $7 \mathrm{dpf}$, the inner ear of zebrafish contains three semicircular channels with associated cristae and the otic vesicle with two maculae and otoliths (the saccule is not separated from the utricle, and the lagena has not even started to form). Based on the size of the zebrafish used by Higgs et al. (2003), their ages likely ranged from 1 month old to adult. At 1-month post fertilization, zebrafish have an inner ear whose gross morphology resembles the inner ear of adult zebrafish, including the three otolithic organs and three semicircular canals with associated ampullae (Platt 1993; Bang et al. 2001). Second, different independent variables and recording methods were used in the present study compared to the study by Higgs et al. (2003). Higgs and his colleagues reported sound pressure thresholds using auditory brainstem recording whereas we reported particle motion threshold using microphonic potential recording from hair cells in the inner ear. A recent report demonstrated differences in threshold between pressure and particle motion measurements for fishes that possess no swimbladder, swimbladder alone, or swimbladder with the Weberian ossicles (Radford et al. 2012), indicating that it would be invalid to directly compare pressure sensitivity with particle motion sensitivity.

In summary, we found that zebrafish increase auditory response and sensitivity during embryonic and early postembryonic development. Our results indicate that the increases in number and density of hair cells in the otocyst may contribute to the enhancement of auditory function during the first week of development in zebrafish. Because the particle motion mode of hearing is shared by all fishes, our findings from zebrafish likely apply to the early ontogenetic development of hearing in other fishes. It is known that zebrafish like other fishes continue to add hair cells to the inner ear postembryonically beyond sexual maturity (Corwin 1983; Lombarte and Popper 1994; Higgs et al. 2002). Whether or not the particle motion sensitivity in zebrafish continues to increase with age beyond the first week of postembryonic development remains to be investigated.

\section{ACKNOWLEDGMENTS}

This work was supported by the National Institute of Deafness and Other Communicative Disorders of the National Institutes of Health (R21DC009879), University of Miami Provost Research Award, and College of Arts and Sciences Gabelli Fellowship. We are grateful to Dr. Tatjana Piotrowsk's lab for providing us the SqET4 transgenic zebrafish. We would like to thank Dr. A. James Hudspeth for his advice during our development of the microphonic recording method. Thanks also to Ricardo Cepeda for excellent fish care; undergraduates Max Frye, Brittany Tyson, Adam Polinsky, Aleks Vantraub, Steven Basart, and Louis Cai for their help in the various aspects of this project; and Lilliann Zamora for her comments on this manuscript.

\section{REFERENCES}

Alderks PW, Sisneros JA (2011) Ontogeny of auditory saccular sensitivity in the plainfin midshipman fish, Porichthys notatus. J Comp Physiol A 197:387-398

Bang PI, Sewell WF, Malicki JJ (2001) Morphology and cell type heterogeneities of the inner ear epithelia in adult and juvenile zebrafish (Danio rerio). J Comp Neurol 438:173-190

Bever MM, FeKETE DM (2002) Atlas of the developing inner ear in zebrafish. Dev Dyn 223:536-543

Buck LMJ, Winter MJ, ReDFern WS, WhitField TT (2012) Ototoxininduced cellular damage in neuromasts disrupts lateral line function in larval zebrafish. Hear Res 284:67-81

Cervi AL, Poling KR, Higgs DM (2012) Behavioral measure of frequency detection and discrimination in the zebrafish, Danio rerio. Zebrafish 9:1-7

Chiu LL, Cunningham LL, Raible DW, Rubel EW, Ou HC (2008) Using the zebrafish lateral line to screen for ototoxicity. J Assoc Res Otolaryngol 9:178-190

Coffin AB, Ou H, Owens KN, Santos F, Simon Ja, Rubel EW, Raible DW (2010) Chemical screening for hair cell loss and protection in the zebrafish lateral line. Zebrafish 7:3-11

Corey DP, Hudspeth AJ (1983) Analysis of the microphonic potential of the bullfrog's sacculus. J Neurosci 3:942-961

Corey DP, García-Añoveros J, Holt JR, Kwan KY, Lin SY, Vollrath MA, Amalfitano A, Cheung El, Derfler BH, Duggan A, Géléoc GS, Gray PA, Hoffman MP, Rehm HL, Tamasauskas D, Zhang DS (2004) TRPA1 is a candidate for the mechanosensitive transduction channel of vertebrate hair cells. Nature 432:723-730

CoRwIN JT (1983) Postembryonic growth of the macula neglecta auditory detector in the ray, Raja clauata: Continual increases in hair cell number, neural convergence, and physiological sensitivity. J Comp Neurol 217:345-356

Ernest S, Rauch GJ, Haffter P, Geisler R, Petit C, Nicolson T (2000) Mariner is defective in myosin VIIA: a zebrafish model for human hereditary deafness. Human Mol Genet 9:2189-2196

FAY RR (1984) The goldfish ear codes the axis of acoustics particle motion in three dimensions. Science 225:951-954

FAY RR, Popper AN (1974) Acoustic stimulation of the ear of the goldfish (Carassius auratus). J Exp Biol 61:243-260

FLOCK $\AA$ (1965) Transducing mechanisms in the lateral line canal organ receptors. Cold Spring Harbor Symp Quantitive Biol 30:133-145

Furukawa T, Ishir Y, Matsuura S (1972) An analysis of microphonic potentials of the sacculus of goldfish. Jpn J Physiol 22:603-616

Gale Je, Marcotti W, Kennedy HJ, Kros CJ, Richardson GP (2001) FM1-43 dye behaves as a permeant blocker of the hair-cell mechanotransducer channel. J Neurosci 21:7013-7025

Gleason MR, Nagiel A, Jamet S, Vologodskaia M, López-Schier H, Hudspetha AJ (2009) The transmembrane inner ear (Tmie) protein is essential for normal hearing and balance in the zebrafish. PNAS 106:21347-21352

Go W, Bessarab D, Korzh V (2010) atp2bla regulates $\mathrm{Ca}^{2+}$ export during differentiation and regeneration of mechanosensory hair cells in zebrafish. Cell Calcium 48:302-313 
Grande T, Young B (2004) The ontogeny and homology of the Weberian apparatus in the zebrafish Danio rerio (Ostariophysi: Cypriniformes). Zool J Linnean Soc 140:241-254

Haddon C, Lewis J (1996) Early ear development in the embryo of the zebrafish, Danio rerio. J Comp Neurol 365:113-128

Haddon C, Mowbray C, Whitfield T, Jones D, Gschmeissner S, Lewis J (1999) Hair cells without supporting cells: further studies in the ear of the zebrafish mind bomb mutant. J Neurocytol 28:837-850

Higgs DM, Souza MJ, Wilkins HR, Presson JC, Popper AN (2002) Age- and size-related changes in the inner ear and hearing ability of the adult zebrafish (Danio rerio). JARO 3:174-184

Higgs DM, Rollo AK, Souza MJ, Popper AN (2003) Development of form and function in peripheral auditory structures of the zebrafish (Danio rerio). J Acoust Soc Am 113:1145-1154

Higgs DM, Lu Z, Mann DA (2006) Hearing and mechanoreception. In: Evan D (ed) The physiology of fishes. CRC Press, Boca Raton, FL, pp 391-429

HudSPETH AJ, COREY DP (1977) Sensitivity, polarity, and conductance change in the response of vertebrate hair cells to controlled mechanical stimuli. Proc Natl Acad Sci USA 74:2407-2411

Kappler JA, Starr CJ, Chan DK, Kollmar R, Hudspeth AJ (2004) A nonsense mutation in the gene encoding a zebrafish myosin VI isoform causes defects in hair-cell mechanotransduction. Proc Natl Acad Sci USA 101:13056-13061

KenYON TN (1996) Ontogenetic changes in the auditory sensitivity of damselfishes (Pomacentridae). J Comp Physiol A 179:553-561

KenYon TN, Ladich F, Yan HY (1998) A comparative study of hearing ability in fishes: the auditory brainstem response approach. J Comp Physiol A 182:307-318

Lechner W, Heiss E, Schwaha T, Glösmann M, Ladich F (2012) Ontogenetic development of Weberian ossicles and hearing abilities in the African bullhead catfish. PLoS One 6:e18511

LOMBARTE A, POPPER AN (1994) Quantitative analysis of postembryonic hair cell addition in the otolithic endorgans of the inner ear of the European hake, Merluccius merluccius (Gadiformes, Teleostei). J Comp Neurol 345:419-428

López-Schier H, Starr CJ, Kappler Ja, Kollmar R, Hudspeth AJ (2004) Directional cell migration establishes the axes of planar polarity in the posterior lateral-line organ of the zebrafish. Dev Cell 7:401-412

Lu Z (2004) Neural mechanisms of hearing in fishes. In: von der Emde G, Mogdam J, Kapoor BG (eds) The sense of fish: Adaptations for the reception of natural stimuli. Narosa Publishing House, New Delhi, pp 147-172

Lu Z, DeSmidt AA (2012) Assessment of hearing in larval zebrafish: Microphonic potential recording. In: Midwinter Research Meeting of the Association for Research in Otolaryngology. San Diego, CA, USA

Lu Z, FAY RR (1996) Two-tone interaction in primary afferents and midbrain neurons of the goldfish, Carassius auratus. Aud Neurosci 2:257-273

Lu Z, POPPER AN (1998) Morphological polarizations of sensory hair cells in the three otolithic organs of a teleost fish: fluorescent imaging of ciliary bundles. Hear Res 126:47-57

Lu Z, POPPER AN (2001) Neural response directionality correlates of hair cell orientation in a teleost fish. J Comp Physiol A 187:453465

Lu Z, Tомснік SM (2002) Effects of a red-tide toxin on fish hearing. J Comp Physiol A 188:807-813

Lu Z, Xu Z (2002) Effects of saccular otolith removal on hearing sensitivity of the sleeper goby (Dormitator latifrons). J Comp Physiol A 188:595-602

Lu Z, Popper AN, FAY RR (1996) Behavioral detection of acoustic particle motion by a teleost fish, Astronotus ocellatus. J Comp Physiol A 179:227-233

Lu Z, Xu Z, Buchser WJ (2010) Frequency coding of particle motion by saccular afferents of a teleost fish. J Exp Biol 213:1591-1601
Metcalfe WK, Kimmel CB, Schabtach E (1985) Anatomy of the posterior lateral line system in young larvae of the zebrafish. J Comp Neurol 233:377-389

Meyers JR, MacDonald RB, Duggan A, Lenzi D, Standaert DG, Corwin JT, COREY DP (2003) Lighting up the senses: FM1-43 loading of sensory cells through nonselective ion channels. J Neurosci 23:4054-4065

Nagiel A, Patel SH, Andor-Ardo D, Hudspeth AJ (2009) Activityindependent specification of synaptic targets in the posterior lateral line of the larval zebrafish. Proc Natl Acad Sci USA 106:21948-21953

Nicolson T (2005) The genetics of hearing and balance in zebrafish. Annu Rev Genet 39:9-22

Nicolson T, Rüsch A, Friedrich RW, Granato M, Ruppersberg JP, NüssLein-VolHard C (1998) Genetic analysis of vertebrate sensory hair cell mechanosensation: the zebrafish circler mutants. Neuron 20:271-283

NishiKaWA S, SASAKI F (1996) Internalization of styryl dye FM1-43 in the hair cells of lateral line organs in Xenopus larvae. J Histochem Cytochem 44:733-741

Nüsslein-Volhard C, Dahm R (2002) Zebrafish: Practical approaches. Oxford University Press, New York

Owens KN, Coffin AB, Hong LS, Bennett KO, Rubel EW, Raible DW (2009) Response of mechanosensory hair cells of the zebrafish lateral line to aminoglycosides reveals distinct cell death pathways. Hear Res 253:32-41

Palmer LM, Mensinger AF (2004) Effect of the anesthetic tricaine (MS-222) on nerve activity in the anterior lateral line of the oyster toadfish, Opsanus tau. J Neurophysiol 92:1034-1041

Parinov S, Kondrichin I, Korzh V, Emelyanov A (2004) Tol2 transposon-mediated enhancer trap to identify developmentally regulated zebrafish genes in vivo. Dev Dynam 231:449-459

Phillips JB, Blanco-Sanchez B, Lentz JJ, Tallafuss A, Khanobdee K, Sampath S, Jacobs ZG, Han PF, Mishra M, Williams DS, Keats BJ, Washbourne P, Westerfield M (2011) Harmonin (Ush1c) is required in zebrafish Müller glial cells for photoreceptor synaptic development and function. Dis Mod Mech 4:786-800

Platt C (1993) Zebrafish inner ear sensory surfaces are similar to those in goldfish. Hear Res 65:133-140

Popper AN, Coombs S (1982) The morphology and evolution of the ear in Actinopterygian fishes. Am Zool 22:311-328

Popper AN, FAY RR (1993) Sound detection and processing by fish: critical review and major research questions. Brain Behav Evol 41:14-38

Popper AN, FAY RR (2011) Rethinking sound detection by fishes. Hear Res 273:25-36

Radford CA, Montgomery JC, Caiger P, Higgs DM (2012) Pressure and particle motion detection thresholds in fish: a re-examination of salient auditory cues in teleosts. J Exp Biol 215:3429-3435

Riley BB, Moorman SJ (2000) Development of utricular otoliths, but not saccular otoliths, is necessary for vestibular function and survival in zebrafish. J Neurobiol 43:329-337

RÜBSMEN R, LIPPE WR (1998) The development of cochlear function. In: Rubel EW, Popper AN, Fay RR (eds) Development of the auditory system. Springer-Verlag, New York, pp 193-270

Shen YC, Jeyabalan AK, Wu KL, Hunker KL, Kohrman DC, Thompson DL, Liu D, Barald KF (2008) The transmembrane inner ear (tmie) gene contributes to vestibular and lateral line development and function in the zebrafish (Danio rerio). Dev Dyn 237:941-952

Sisneros JA (2007) Saccular potentials of the vocal plainfin midshipman fish, Porichthys notatus. J Comp Physiol A 193:413424

Sisneros JA, Bass AH (2005) Ontogenetic changes in the response properties of individual, primary auditory afferents in the vocal plainfin midshipman fish Porichthys notatus Girard. J Exp Biol 208:3121-3131 
Söllner C, Rauch GJ, Siemens J, Geisler R, Schuster SC, Tübengen 2000 Screen Consortium, Müller U, Nicolson T (2004) Mutations in cadherin 23 affect tip links in zebrafish sensory hair cells. Nature 428:955-959

Starr CJ, Kappler JA, Chan DK, Kollmar R, Hudspeth AJ (2004) Mutation of the zebrafish choroideremia gene encoding Rab escort protein 1 devastates hair cells. Proc Natl Acad Sci USA 101:2572-2577

Tanimoto M, Ota Y, Horikawa K, Oda Y (2009) Auditory input to CNS is acquired coincidentally with development of inner ear after formation of functional afferent pathway in zebrafish. $J$ Neurosci 29:2762-2767

TANimoto M, Ota Y, Inoue M, Oda Y (2011) Origin of inner ear hair cells: Morphological and functional differentiation from ciliary cells into hair cells in zebrafish inner ear. J Neurosci 31:3784-3794

Томснік SM, Lu Z (2006) Modulation of auditory signal-to-noise ratio by efferent stimulation. J Neurophysiol 95:3562-3570

Trapani JG, Nicolson T (2010) Physiological recordings from zebrafish lateral-line hair cells and afferent neurons. Meth Cell Biol 100:219-231

VAsconcelos RO, LAdich F (2008) Development of vocalization, auditory sensitivity and acoustic communication in the Lusitanian toadfish Halobatrachus didactylus. J Exp Biol 211:502-509
Waterman RE, Bell DH (1984) Epithelial fusion during early semicircular canal formation in the embryonic zebrafish, Brachydanio rerio. Anat $\operatorname{Rec} 210: 101-114$

Westerfield M (2007) The zebrafish book: A guide for the laboratory use of zebrafish (Danio rerio). University of Oregon Press, Eugene, Oregon

Whitfield TT (2002) Zebrafish as a model for hearing and deafness. J Neurobiol 53:157-171

Yariz K, Duman D, Seco CZ, Dallman J, Huang M, Peters T, Sirmaci A, Lu N, Schraders M, Skromne I, Oostrik J, DiazHorta O, Young Ji, Tokgoz-Yilmaz S, Konukseven O, Shahin H, Hetterschijt L, Kanaan M, Oonk AMM, Edwards YJK, Li H, Atalay S, Blanton S, DeSmidt AA, Liu XZ, Pennings RJe, Lu Z, Chen ZY, Kremer H, Tekin M (2012) Mutations in OTOGL, encoding the inner ear protein Otogelin-like, cause moderate sensorineural hearing loss. Am J Hum Genet 91:872-882

Zamora L., Lu Z (2013) Alcohol-induced morphological deficits in the development of octavolateral organs of the zebrafish (Danio rerio). Zebrafish 10. doi:1089/zeb.2012.0830.

ZedDiEs RG, FAY RR (2005) Development of acoustically evoked behavioral response in zebrafish to pure tones. J Exp Biol 208:1363-1372 